\title{
Hermann Cohen and Kant's Concept of Experience
}

\author{
Nicholas F. Stang
}

\section{Introduction}

Hermann Cohen's 1871 classic, Kants Theorie der Erfahrung, had a formative influence, not only on the Marburg school's reading of Kant, but on their entire conception of philosophy. This influence was further magnified by the substantially revised and expanded second edition of 1885 and the yet further expanded third edition of 1918. Neo-Kantianism was the dominant philosophical movement in Germany in the late nineteenth and twentieth centuries, which means that a work, ostensibly, of Kant scholarship had an influence on the development of German philosophy that few works of secondary literature can claim.

Although Cohen's reading of Kant was massively influential, it was, and remains, just as controversial. From the late nineteenth century to today, it has attracted everything from meticulous scholarly critique $^{1}$ to brusque dismissal. ${ }^{2}$ It has not fared significantly better even among Cohen scholars, many of whom

\footnotetext{
${ }^{1}$ E.g. Vaihinger's careful point-by-point unraveling of Cohen's reading of the Transcendental Aesthetic in Vaihinger 1887, vol. 2. Even Vaihinger allows his contempt to shine through at moments: "Unverständlich, wie so häufig, Cohen. Th. d. Erf." (Vaihinger 1892, vol. 2, p. 138). Thanks to Des Hogan for pointing me to that remark.

${ }^{2}$ For instance, Heidegger: "die Absicht der Kritik der reinen Vernunft bleibt demnach grundsätzlich verkannt, wenn dieses Werk als 'Theorie der Erfahrung' oder gar als Theorie der positive Wissenschaft ausgelegt wird" (Heidegger 1929, pp. 16-17). Cf. Ebbinghaus, J. 1954.
}

\footnotetext{
N.F. Stang $(\triangle)$

Department of Philosophy, University of Toronto, Toronto, Canada

E-Mail: nick.stang@gmail.com
} 
brush its interpretations aside as mistaken. ${ }^{3}$ The great scholar of Neo-Kantianism Klaus Köhnke begins his discussion of the Kant book by questioning whether it is really an historical interpretation at all. ${ }^{4}$ Cohen's interpretation is something of a "dead dog" in the contemporary Kant literature as well. It is hard to find a single major living Kant scholars who discusses Cohen's main interpretive claims in any detail. Even Michael Friedman, who evinces a deep appreciation for Cohen's student Ernst Cassirer, and, of contemporary Kant scholars, is the closest in spirit to Marburg, mentions Cohen in neither of his major works on Kant. ${ }^{5}$

It is not hard to explain why many have rejected Cohen's reading. From reading the Deduction and the Aesthetic as depending on the Principles of Experience, to claiming that Dinge an sich selbst are the asymptotic limit of scientific inquiry, $K T E$ (as I will abbreviate it) is replete with claims that historically and textually grounded readers of Kant are, I think, right to be suspicious of. ${ }^{6}$

In this essay I offer a partial rehabilitation of Cohen's Kant interpretation. In particular, I will focus on the center of Cohen's interpretation in KTE, reflected in the title itself: his interpretation of Kant's concept of experience. "Kant hat einen neuen Begriff der Erfahrung entdeckt,"7 Cohen writes at the opening of the first edition of $K T E$ (henceforth, $K T E^{1}$ ), and while the exact nature of that new concept of experience is hard to pin down in the 1871 edition, he states it succinctly in the second edition (henceforth $K T E^{2}$ ): experience is Newtonian mathematical natural science. ${ }^{8}$ While this equation of experience with mathematical natural science has few contemporary defenders, I believe it is substantially correct, with one important qualification. Kant uses the term Erfahrung in a number of different senses in the Kritik der reinen Vernunft (henceforth, $K r V$ ). I will argue that a central, and neglected, sense of that key technical term aligns with Cohen's reading; what Kant

\footnotetext{
${ }^{3}$ Köhnke (1986, pp. 273-275), Brandt (1993, pp. 37-54), Poma (1997, pp. 18, 48-53); and Kuehn (2009, pp. 115-121). Beiser (2014, p. 489) is more balanced, but ultimately is critical of Cohen's reading.

${ }^{4}$ Köhnke (1986, p. 273). Cf. Luft (2015, pp. 43-48).

${ }^{5}$ Friedman (1992) and (2013). This, despite the fact that this sentence of Cohen's could almost function as a summary of Friedman's decade-long engagement with Kant and Newton: "the transcendental method arose through a reflection upon the Philosophiae naturalis principia mathematica" (KTE ${ }^{2}$, p. 67).

${ }^{6}$ It should also be noted, that whatever its flaws, contemporary Kant scholarship is deeply indebted to $K T E$, one of the first works to attempt a rigorous, textually grounded interpretation of Kant's thought. In doing so, KTE helped create the scholarly tradition that now largely rejects it.

${ }^{7}$ The very next sentence reads: "die Kritik der reinen Vernunft ist Kritik der Erfahrung." I will not attempt to rehabilitate that claim, for, as many scholars have pointed out, the $K r V$ is fundamentally about the possibility of metaphysics, and only secondarily about experience (because the synthetic a priori cognitions of metaphysics are made possible by their relation to experience).

8“Kants Aufgabe ist also zunächst die Prüfung und Kennzeichnung des Erkenntniswertes und des Gewissheitsgrundes der Netwonschen Naturwissenshcaft, welche er be dem Drohwort der Erfahrung fasste" $\left(K T E^{3}\right.$, p. 93); in the first edition see $K T E^{1}$, pp. 206, 208. On the development in Cohen's reading of Kant see Edel's Introduction to Werke I.1, pp. 20*, 22-23*.
} 
sometimes refers to as 'universal experience' (sometimes, simply 'experience') is, in broad outlines, correctly interpreted by Cohen as mathematical natural science.

In §2 I distinguish several different senses in which Kant uses the key term Erfahrung, focusing on one of them, which, following Kant, I refer to as 'universal experience.' The next two sections are devoted to articulating precisely what universal experience is. In $\$ 3$ I argue that one desideratum is that the universal experience must be able to play a key role in Kant's transcendental idealism: the actual spatiotemporal objects there are, and their actual formally contingent properties (those not determined by the form of experience itself), are grounded in the content of universal experience. In \$4 I provide an account of universal experience that meets this desideratum using a 'limit' construction. ${ }^{9}$ In $\$ 5$ I summarize the core ideas of Cohen's reading of Erfahrung as Newtonian mathematical natural science, prising apart what I take to be the salvageable core of his proposal from some of his less promising claims. In particular, I argue that Cohen was mistaken in identifying 'universal experience' with Newton's specific scientific theory, or, for that matter, any particular scientific theory whatsoever. Universal experience, on my reading, is akin to what is now called "final science," the complete scientific account of all objects in space and time, which we never fully grasp, but, at best, asympototically approach through our continuing investigation of nature. I conclude by using this conception of universal experience to rehabilitate, partly, one of Cohen's most notorious doctrines, his claim that things in themselves are the asymptotic limit of science (experience, on Cohen's conception). I argue that this is correct for what Kant calls "things in themselves in the empirical sense,"10 which I interpret as the fully contingent properties actually possessed by objects in space and time. Cohen is right to think that such properties are the properties objects are represented as having at the asymptotic limit of science (as defined in $\S 4)$. However, he was wrong to conflate these "empirical things in themselves" with "transcendental things in themselves," the non-spatiotemporal beings that appear to us as the spatiotemporal objects of experience/science.

If the argument of this paper is correct, our understanding of both Kant and Cohen must be revised. With respect to Kant, the central notion of at least the Transcendental Analytic, the possibility of experience, involves a much less perceptual/phenomenological and much more scientific conception of experience than many have allowed. With respect to Cohen, Kants Theorie der Erfahrung not only

\footnotetext{
${ }^{9}$ The closely related (though distinct) notion of the infinitesimal plays a key role in Cohen's philosophical development after 1871 as well as in his mature theory of critical idealism. For reasons of space I cannot here discuss the relation between my invocation of the Bolzano-Weierstrass $\varepsilon-\delta$ definition of limit and Cohen's concept of the limit and the infinitesimal. For Cohen's concept of limits and the infinitesimal method see PIM.

${ }^{10} \mathrm{An}$ admittedly free rendering of this remark: "Denn in diesem Falle gilt das, was ursprünglich selbst nur Erscheinung ist, z. B. eine Rose, im empirischen Verstande für ein Dinge an sich selbst” (A30/B45).
} 
massively influenced the development of nineteenth- and twentieth-century German philosophy, but, in doing so, offered a valuable corrective to a tendency, still prevalent today, to overlook a central notion of experience in $\mathrm{KrV}$.

\section{Different senses of Erfahrung in Kant}

Although Erfahrung is one of the central notions of the $\mathrm{KrV}$ Kant uses this term in several different senses, without explicitly distinguishing them. In this section I attempt to prise apart these different senses. ${ }^{11}$

1. The common notion. One of the roles the concept of experience plays in the $\mathrm{KrV}$ is to express Kant's disagreement with empiricist theories of cognition, like those of Locke and Hume. Kant denied what Locke and Hume maintained, that, in Kant's words, all of our cognition "entspringt ... aus Erfahrung" (B1). In order to express this disagreement Kant needs a 'neutral' concept of experience, one that does not contain specifically Kantian assumptions about the nature of experience. Otherwise, in claiming that Locke and Hume held that all cognition "entspringt aus" experience he would be attributing to the empiricists a doctrine they did not hold.

Indeed, in various passages we find Kant using "Erfahrung" to refer to a neutral conception of experience, one that Locke and Hume could recognize. ${ }^{12}$ For instance, in the B Introduction Kant writes: "Erfahrung lehrt uns zwar, daß etwas so oder so beschaffen sei, aber nicht, daß es nicht anders sein könne (B3)."13 But in at least one sense of "experience," Kantian experience does involve representing a necessary causal connection (see below), so in this passage, and others like it, he must mean "Erfahrung" in a different, less robust, sense. In this passage, then, Kant is giving the empiricists their due: there is a relatively minimal notion of experience, the empiricist one, on which experience does not tell us what is necessarily the case. ${ }^{14}$

\footnotetext{
${ }^{11}$ I have explored some of the same themes in Stang (2015a). An earlier, less adequate, account of universal experience can be found in Stang (2012).

${ }^{12}$ Namely, ideas (Locke) or impressions (Hume) of sensation and reflection.

${ }^{13}$ The same sentence is repeated nearly word for word in Prol, Ak. 4:292.

${ }^{14}$ Another possibility is that there is an ambiguity in the notion of 'necessity' involved. However, if we accept the taxonomy of the kinds of necessity argued for in Stang (2011), this does not hold. For of the four kinds of necessity distinguished there-logical, formal, empirical, and noumenal-only two are relevant in this context (formal, empirical) and it is both the case that (a) Locke and Hume would deny that experience contains necessities of either kinds and (b) Kantian experience does acquaint us with such necessities. The conclusion argued for in the main text thus holds: Kant's claim at B3 involves something other than his 'official' notion of experience, a more minimal notion of experience he is willing to deploy to express his (limited) agreement with the empiricists Locke and Hume. For more on Kantian modalities, see Stang (2016a).
} 
2. Empirical cognition. In some contexts, Kant defines experience as "empirical cognition" where "cognition" (Erkenntnis) refers to thinking a sensibly given object under a concept. ${ }^{15}$ On this definition, to experience (empirically cognize) an object is to think a sensibly given object under a concept. Although this 'cognitive' notion of experience is one that Locke and Hume may have the philosophical resources to account for, it is not what they have in mind when they claim that all our ideas arise from experience. ${ }^{16}$ They mean something more minimal by 'experience,' roughly, any conscious sensory impression whatsoever.

3. Synthetic unity of perceptions. In what is perhaps the dominant use of the term "experience" in the $K r V$, Kant at several points defines experience as a synthetic unity of perceptions. ${ }^{17}$ This definition is constitutively linked to the distinction between perception and experience, so we must first understand that distinction. ${ }^{18}$

Kant's principal characterization of the distinction between these two kinds of representation is in terms of their relation to their object: perception of the intuition of an object versus experience of its existence. ${ }^{19}$ He defines perception as empirical consciousness of appearance (B162), which I take to mean: consciously apprehending a manifold of empirical intuition. Apprehending a sensory

\footnotetext{
${ }^{15}$ For instance, at B147 he writes that the categories "dienen nur zur Möglichkeit empirischer Erkenntnis. Diese aber heißt Erfahrung"; at the beginning of the same paragraph he writes: "sich einen Gegenstand denken und einen Gegenstand erkennen, ist also nicht einerlei. Zum Erkenntnisse gehören nämlich zwei Stücke: erstlich der Begriff, dadurch überhaupt ein Gegenstand gedacht wird (die Kategorie), und zweitens die Anschauung, dadurch er gegeben wird" (B146).

${ }^{16}$ This corresponds, roughly, to applying an abstract idea to an idea of sensation or reflection (Locke) or applying an abstracted idea to an impression of sensation or reflection (Hume). It would make no sense for Locke or Hume to claim that all of our ideas arise from experience in this Kantian 'cognitive' sense (experience \#2), for experience is here defined in terms of applying an idea to a sensory impression.

${ }^{17}$ A110, A124 ff., A156/B195, B161, B218, A213/B260, and A183/B226.

${ }^{18}$ The Analogies of Experience are structured around the distinction between perception (Wahrnehmung) and experience (Erfahrung); see especially B218-219. In thinking about Kant's technical notion of perception (Wahrnehmung), its difference from experience on the one hand and empirical intuition on the other, as well as its role in the Analogies, I have benefited tremendously from reading Clinton Tolley's unpublished paper "Kant on the distinction between perception and experience." My discussion in the rest of this section is deeply indebted to Tolley's excellent work.

${ }^{19}$ Consider that the titles of the Principles of Experience, at least in the A Edition, speak of "Erscheinungen [...] ihre Anschauung nach (Axiomen der Anschauung, A162)", "das Reale, was ein Gegenstand der Empfindung ist" (Antizipationen der Wahrnehmung, A166), and finally "alle Erscheinungen stehen, ihrem Dasein nach, [...]" (A176; my emphasis throughout). A160/B199, A178/B210. So we proceed from the principle of the intuition of appearances (Axioms) to the principle of the perception of reality in appearances (Anticipations) to the principle of the experience of their existence (Analogies). I owe appreciation of this point to Tolley "Kant on the distinction."
} 
manifold is being conscious of a single spatial (outer) or temporal (inner) field in which there is qualitative differentiation and being conscious of it as such. ${ }^{20}$ The difference between perceiving and experiencing is the difference between being consciously aware of a sensory manifold (qualitatively differentiated spatial or temporal field) and thinking of that sensory manifold as the appearing of some object in space. ${ }^{21}$ When Kant claims that we experience the existence of an object I take him to mean: we experience an object as existing in some public intersubjectively accessible space, an object that can be experienced by different subjects and reidentified over time. ${ }^{22}$

This is the sense of experience Kant is trying to capture when he announces in the $\mathrm{B}$ edition that the principle of the Analogies of Experience is that "experience is possible only through the representation of a necessary connection of perceptions" (B218). Representing a perceived object (an object whose sensory manifold we consciously apprehend) as existing requires synthesizing various actual and counterfactual perceptions (perceptions we would have under the right conditions) using the pure concepts of the understanding, in particular, the categories of relation. The argument of the Analogies is that this combination of perceived manifolds requires combining them according to necessary laws corresponding to each category of relation. While it is not clear that anything in Kant's complex taxonomy of the mind and its states corresponds to the contemporary notion of 'perceptual experience' this notion of experience (synthesized unity of perceptions) comes closest: a perceptual awareness of a public object available for perception by other subjects and reidentifiable across perceptions. Consequently, I will refer to it as perceptual experience, or p-experience for short. To wrap up a loose end,

\footnotetext{
${ }^{20}$ Kant writes in the A Deduction: "das erste, was uns gegeben wird, ist Erscheinung, welche, wenn sie mit Bewusstsein verbunden ist, Wahrnehmung heißt [...] Weil aber jede Erscheinung ein Mannigfaltiges enthält, mithin verschiedene Wahrnehmungen in Gemüte an sich zerstreut und einzeln angetroffen werden, so ist eine Verbindung derselben nötig, welche sie in dem Sinne selbst nicht haben können. Es ist als in uns ein tätiges Vermögen der Synthesis eises Mannigfaltigen, welches wir Einbildungskraft nennen, und deren unmittelbar an den Wahrnehmungen ausgeübte Handlung ich Apprehension nenne. Die Einbildungskraft soll nämlich das Mannigfaltige der Anschauung in ein Bild bringen; welcher muß sie also die Eindrücke in ihre Tätigkeit aufnehmen, d. i. apprehendieren" (A120). Again, thanks to Clinton Tolley for drawing my attention to passages like this.

${ }^{21}$ I mean 'appearing' here in the empirical sense, in which it is used to mark the difference between the real empirical properties of objects in space and time (phenomena) and how they appear to perceivers' sense organs at a given time under given conditions. The transcendental sense of 'appearing' marks the difference between the real empirical properties of objects in space and time (phenomena) and their unknowable inner constitution (noumena). In this paper I am trying to remain as neutral as possible on the second distinction, which has received the lion's share of attention from commentators on Kant's idealism. For the empirical appearance/ thing in itself distinction, and its difference from the transcendental distinction, see A29-30/B45 and A45-46/B62-63.

${ }^{22} \mathrm{By}$ 'existence' he cannot mean the causal efficacy of the object, as he seems to in other contexts (e.g. Ak. 4:468), for that would render the conclusion of the second and third Analogies nearly trivial: to represent an object as causally efficacious we must represent is using the categories $<$ cause-effect $>$ and $<$ community $>$.
} 
perception and experience, in Kant's technical sense, are both instances of experience in sense \#2: they both involve thinking a sensibly given object under a concept, either a sensory manifold (perception) or an existing object (experience). ${ }^{23}$

4. Causal-hypothetical experience. Kant's core examples of experience in the Analogies are examples where I represent some consciously apprehended sense manifold as the direct appearing of an existing (publicly available) object. For instance, I see a boat sailing downstream or the parts of a house. ${ }^{24}$ However, in the Postulate of Actuality Kant introduces the possibility of experiencing an object 'indirectly' when he claims that I can experience an all-pervading magnetic matter (we would now say 'magnetic field') by experiencing the movement of iron filings in the presence of a magnet, and inferring, by the Second Analogy, some medium by which the magnet moves the iron filings. ${ }^{25}$ This kind of case does not fit the model of p-experience described above because, in cases like this, the perceived sensory manifold is not an appearance of the experienced object (the magnetic field). Instead, the relation is more indirect: the sensory manifold is the appearance of the moving iron filings, from which I infer the existence of the magnetic field. To mark the difference between this more indirect notion of experience and p-experience I will refer to it as causal-hypothetical or ch-experience.

In the Postulate of Actuality Kant emphasizes that the difference between what I am calling p-experience and ch-experience depends on the contingent limitations of our sense organs. ${ }^{26}$ Since transcendental philosophy is supposed to abstract from contingent facts like these, the difference between p-experience and ch-experience is not very significant for transcendental philosophy. He goes on to assert a constitutive tie between these two kind of experience: anything that can be an object of ch-experience can also be an object of p-experience for some discursive spatiotemporal intellect, though not necessarily one with our contingent sense organs. ${ }^{27}$ Any object that causally interacts with the objects we directly p-experience is such as to be directly detectable by a discursive spatiotemporal intellect with appropriately constituted sense organs. Since all objects in space and time causally interact with the objects we directly p-experience (Third Analogy) it follows that all objects of ch-experience are such as to be directly detectable by a discursive spatiotemporal intellect with appropriately constituted sense organs.

\footnotetext{
${ }^{23}$ Kant makes this point about experience in sense \#3 (synthetic unity of perceptions) at B218, but it follows immediately from his definition of experience (\#2 on my reading) as empirical cognition at B147 and the discussions of intuition and perception in the Axioms and the Anticipations.

${ }^{24}$ A192/B237 and A190/B235, respectively.

${ }^{25}$ A225-226/B273.

26“"Denn überhaupt würden wir, nach Gesetzen der Sinnlichkeit und dem Kontext unserer Wahrnehmung, in einer Erfahrung auch auf die unmittelbare empirische Anschauung derselben stoßen, wenn unsere Sinnen feiner wären, deren Grobheit die Form möglicher Erfahrung überhaupt nichts angeht" (A226/B273).

${ }^{27}$ A226/B273.
} 
Consequently, I will refer to p-experience and ch-experience collectively as pchexperiences. Pch-experience includes everything of which we have direct perceptual experience ( $\mathrm{p}$-experience) as well as everything that is posited to explain the objects of our direct perceptual experience (ch-experience) through spatiotemporal causal interaction governed by the Analogies of Experience. ${ }^{28}$

5. Universal experience. In other contexts, though, Kant defines experience as a maximal unity of such perceptual and causal-hypothetical experiences. For instance, in the A Deduction he writes:

Es ist nur eine Erfahrung, in welcher alle Wahrnehmungen als im durchgängigen und gesetzmäßigen Zusammenhange vorgestellt werden: ebenso, wie nur ein Raum und Zeit ist, in welcher all Formen der Erscheinung und alles Verhältnis des Seins oder Nichtseins stattfinden. Wenn man von verschiedenen Erfahrungen spricht, so sind es nur so viel Wahrnehmungen, sofern solche zu einer und derselben allgemeinen Erfahrung gehören. $(\mathrm{A} 110)^{29}$

I will refer to this notion of experience as universal experience, or u-experience for short. To understand Kant's notion of universal experience it will be helpful to contrast it with pch-experience. First of all, as Kant says quite clearly, there can be only one u-experience, but there can be multiple pch-experiences: my experience of this table, this piece of paper, the magnetic field, the solar system, etc. If we take him at his word, this means there is only one u-experience period: that you and I do not have different u-experiences, but our pch-experiences count as experience (in the 'universal' sense) only to the extent that they cohere with one intersubjectively valid u-experience. Secondly, there are pch-experiences that are not part of the single u-experience; for instance, if I p-experience this chair as being taller than this table, but later experiences do not cohere with this, then the "complete and lawful connection of all experiences" does not represent this chair as being taller than this table, so my p-experience is not part of the content of the one single u-experience. Likewise, if I posit the existence of a magnetic field to explain the movement of iron filings but later discover that this is due to some other cause, my initial pch-experience of the magnetic matter does not count as an experience in the more demanding sense of A110 (it does not cohere with the "complete and lawful connection of all experience"). Thirdly, the content of u-experience will be much more complex and more determinate than the content of any single pchexperience; my pch-experience may represent some regularity and some degree of lawfulness in its objects, and represents them as determinate in respect of some properties (e.g. causal properties), but u-experience represents all such objects in "durchgängig und gesetzmäßigen Zusammenhang" with one another; the degree

\footnotetext{
28“Wo also Wahrnehmung und deren Anhang nach empirischen Gesetzen hinreicht, dahin reicht auch unsere Erkenntnis vom Dasein der Dinge" (A226/B273).

${ }^{29}$ One also finds the idea of a single 'universal' experience at A230/B283, A493/B521, A495/ B524, and A582/B610.
} 
of lawfulness and regularity in its content will be much greater, and it will represent its objects as determinate with respect to a wider range of properties than any individual pch-experience does.

\section{Universal Experience and Transcendental Idealism}

In the next two sections I go into more detail about u-experience, which, as I will argue in $\$ 5$, most closely corresponds to Cohen's conception of Erfahrung. My method will be somewhat indirect. In this section, I will argue that u-experience must play a particular role in Kant's transcendental idealism: it must ground the actual formally contingent properties of objects. In the next section I offer a construction of u-experience on which it can do precisely that. In neither of these two sections is my argument primarily textual; instead, I try to make explicit aspects of Kant's notion of universal experience that remain, for the most part, implicit in the $K r V .^{30}$

The possibility of objects in space and time having various properties (e.g. causal properties) depends upon, or consists in, the possibility of our experiencing such objects as having these properties. This much is relatively clear from the $K r V$ and is relatively uncontroversial among Kant scholars. However, matters become much less clear and uncontroversial when we turn to actuality. Consider that the particular objects we experience in space and time are not mandated by the forms of experience alone; it is contingent, given our sensible and intellectual forms of experience, that these objects exist. ${ }^{31}$ Consider further that many of their fully determinate spatiotemporal positions and causal powers (e.g. the laws that govern their interaction) are not mandated by the forms of experience either. I will call these formally contingent properties, properties that are compatible with the forms of experience (hence they are formally possible) but which are not grounded in the forms of experience (hence they are not formally necessary). ${ }^{32}$ What is it in virtue of which there are the objects in space and time there actually are, with the formally contingent properties they actually have? What grounds actuality? To answer these questions fully we need to fill in these blanks:

\footnotetext{
${ }^{30}$ The material in this section dovetails with the discussion in Stang (2016b), where I use similar arguments to critique the interpretation of Allais (2015).

${ }^{31}$ This holds true regardless of which specific notion of experience from $\S 1$ we have in mind.

${ }^{32}$ These notions are defined as follows in Stang (2011) (cf. Stang 2016, Sect. 7.3):

Formal possibility It is formally possible that $p$ just in case it is compatible with our forms of experience that $p$.

Formal necessity It is formally necessary that $p$ just in case it is incompatible with our forms of experience that not- $p$.
} 
(Ex) There is actually an object in space and time that has formally contingent property $\mathrm{F}$ if and only if

(Prop) Where $x$ is an object in space and time, $x$ has formally contingent property $\mathrm{F}$, if and only if .33

It is understood, in both cases, that the left-hand side of the biconditional is true in virtue of the right-hand side. We are not looking merely for necessary and sufficient conditions; we are looking for the grounds of the left-hand side. To take a concrete example, let us assume that there actually is a spatiotemporal object in some distant region of space R. What grounds this fact? Knowing how to answer this question in general is knowing how to fill in the blank in (Ex); in the example, $\mathrm{F}$ is the property of being an object in region $\mathrm{R}$.

To answer these questions the natural place to turn is the Postulates of Empirical Thinking in General, in particular the Postulate of Actuality: "was mit den materialen Bedingungen der Erfahrung (der Empfindung) zusammenhängt, ist wirklich" (A218/B266). In the further discussion of this Postulate Kant makes a point we discussed above: we can experience objects we cannot perceive (A225/ B272). In my terminology this means we can experience objects we cannot p-experience and I coined the term ch-experience (more generally, pch-experience) to cover such cases. In the next paragraph Kant writes:

Man kann aber auch vor der Wahrnehmung des Dinges, und also comparative a priori das Dasein derselben erkennen, wenn es nur mit einigen Wahrnehmungen, nach den Grundsätzen der empirischen Verknüpfung derselben (den Analogien) zusammenhängen. (A225/ B272)

On one reading of this passage Kant is claiming that what is actual is what stands in causal relation to what we perceive. On such a reading, Kant is offering this account of what grounds the actual existence of objects in space and time:

(Ex.1) There is actually an object in space and time that has formally contingent property $\mathrm{F}$ if and only if (i) there is actually an object in space and time that has property $\mathrm{F}$ and (ii) it stands in causal connection with our perceptions.

But notice that (i) is merely the antecedent of (Ex. 1); this analysis is circular. If we weaken (i) to the requirement that there possibly is an object in space and time that has property $\mathrm{F}$ then we get absurd results. Kant's definition of possibility in the Postulates is "was mit den formalen Bedingungen der Erfahrung (der Anschauung und den Begriffen nach) übereinkommt, ist möglich" (A218/B265).

\footnotetext{
${ }^{33}$ These formulae have to be distinguished because existence is not a real predicate; we cannot assimilate the fact there is an object with property $\mathrm{F}$ to the fact that this object has some other property, e.g. the property of existing. Consequently, existential facts need to be formulated in general terms, as in Ex (e.g. there is an $x$ such that Fx). The left-hand side of (3) should not have the form 'appearance $a$ exists' because existence is not a predicate some objects have and others lack - in other words, if the sentence 'Appearance $a$ exists' is well-formed (the singular term refers) then it is true. See Stang (2015b) and (2016a) for further discussion.
} 
This would entail that for every object whose interaction with what we perceive is consistent with the intellectual and sensible form of our experience, there actually is such an object. For instance, if it is consistent with the intellectual and sensible form of our experience that the motion of iron filings in the presence of a magnet is due to the presence of an immediate magnetic attraction-at-a-distance, and it is consistent with those forms that it is due to an "all-pervading" magnetic matter, then both exist. This, I take it, is absurd.

Another possibility suggested by the Postulates discussion of actuality might be:

(Ex.2) There is actually an object in space and time that has formally contingent property $\mathrm{F}$ if and only if we pch-experience such an object on the basis of our actual perceptions.

But this has implausible consequences all its own: it entails that what actually exists now is exhausted by what we pch-experience now. Consequently, as our scientific understanding of nature increases and we pch-experience more of it, previously non-existent entities come into existence. But Kant is a scientific realist in at least this weak sense: he thinks there are things in the physical universe that we have not yet discovered. We do not create them in scientific inquiry. ${ }^{34}$

Some readers might wonder whether Kant needs an answer to the questions I have posed, i.e. whether he needs to be able to fill in the blanks in (Ex) and (Prop). Kant could, on this line of thought, rest content with an epistemic account of how we can have knowledge of actuality (through perception and the transcendental principles of experience) but does not require a metaphysical account of what it is in virtue of which the objects there actually are exist and have their actual formally contingent properties. However, I do not think Kant intended to rest content with an epistemic account, nor do I think he could do so, consistent with his other theoretical commitments. The Postulates are principles that give the meaning of modal categories, when those categories are applied to spatiotemporal phenomena. ${ }^{35}$ They are not merely epistemic principles of how we can acquire epistemic warrant for judgments about such phenomena. ${ }^{36}$

But there are purely philosophical reasons why Kant requires an answer to (Ex) and (Prop). Consider what I will refer to as the skeptical scenario: our scientific theory of the natural world, even at its idealized limit, is inaccurate about what spatiotemporal phenomena there actually are and what (formally contingent) properties they have. In the next section I will go into significant further detail about

\footnotetext{
${ }^{34}$ See Allais (2015, p. 47) and Langton (1998, pp. 144-145) for discussion.

35“"Eben um deswillen sind auch die Grundsätze der Modalität nichts weiter, als Erklärungen der Begriffe der Möglichkeit, Wirklichkeit und Notwendigkeit in ihrem empirischen Gebrauche" (A219/B266).

${ }^{36}$ The Postulate of possibility (quoted in the main text) does give, for instance, merely epistemic conditions under which we can obtain justification for judgments about possibility. It tells us what possibility is for empirical objects (see previous note).
} 
what the "idealized limit of natural scientific theory" is, but here it will suffice to offer a mere sketch. In the skeptical scenario our natural scientific theorizing eventually converges to a stable equilibrium theory about what objects there are and what formally contingent properties they have, and after a certain point it never changes (other than to further refine predicted values of magnitudes within a limited range). I take it that the skeptical scenario, where such an idealized scientific theory is false, is impossible given Kant's transcendental idealist theory of spatiotemporal objects (the subject matter of natural scientific theories). If it were possible for our natural-scientific experience, even at its idealized limit, to be false of physical objects in space and time, I do not know how it could be the case, as Kant states, that "es sind demnach die Gegenstände der Erfahrung niemals an sich, sondern nur in der Erfahrung gegeben, und existieren außer derselben gar nicht" (A493/B520). ${ }^{37}$ Kant therefore must deny that the skeptical scenario is possible. What is more, he needs an explanation of why the skeptical scenario is impossible, which must take the form of an account of what it is in virtue of which there are the spatiotemporal objects there actually are with the formally contingent properties they actually have, which explains why idealized natural-scientific experience cannot be inaccurate about these matters.

The next obvious place to turn in the $K r V$ for an answer to (Ex) and (Prop) is the section of the "Antinomial conflicts of pure reason" titled "Transcendental idealism as the key to solving the cosmological dialectic" (A490-507/B518-535). Kant says several things in that section that suggest an answer along the lines of (Ex.1) or (Ex.2). ${ }^{38}$ However, some remarks in this section suggest a modal or counterfactual answer to (Ex), for instance:

daß es Einwohner im Monde geben könne, ob sie gleich kein Mensch jemals warhgenommen hat, muß allerdings eingeräumet werden, aber es bedeutet nur so viel: daß wir in dem möglichen Fortschritt der Erfahrung auf sie treffen könnten (A492-3/B521).

This naturally suggests the following account:

(Ex.3) There is actually an object in space and time that has formally contingent property $\mathrm{F}$ if and only if we could experience an object with property $\mathrm{F}$.

But we now have the same problem that such a modal analysis faced above. If it is consistent with the forms of experience that we experience a unicorn in $\mathrm{R}$, on

\footnotetext{
${ }^{37}$ The possibility of the skeptical scenario should not be confused with the fact that objects we experience are the appearances of things we can never know, or that perhaps the very objects we experience also have inner natures we can never know (depending on how one interprets Kant's transcendental idealism). The skeptical scenario concerns how these things in themselves appear to us, not how they are in themselves. In the skeptical scenario, the existence of these appearances and their empirical properties (how they appear to us) could be in principle inaccessible to our natural-scientific experience.

${ }^{38}$ E.g. "alles ist wirklich, was mit einer Wahrnhemung nach Gesetzen des empirischen Fortgangs in einem Kontext steht. Sie sind also alsdenn wirklich, wenn sie mit meinem wirklichen Bewußtsein in einem empirischen Zusammenhange stehen, ob sie gleich darum nicht an sich, d.i. außer diesem Fortschritt der Erfahrung, wirklich sind" (A493/B521).
} 
this analysis, it follows that there actually is a unicorn in R. Matters are not helped if, to anticipate the next section slightly, we understand possible experience here as possible u-experience, the "totality" of experience we discussed briefly in $\S 2$. Formally possible u-experience is experience compatible with the form of u-experience, but the matter of u-experience is not determined by its form alone. So any object, experience of which is compatible with the form of $\mathrm{u}$-experience, actually exists, according to (Ex.3). As before, this massively over-generates actual objects.

Elsewhere, Kant suggests a conditional analysis of actuality: "vor der Wahrnehmung eine Erscheinung ein wirkliches Ding nennen, bedeutet entweder, daß wir im Fortgang der Erfahrung auf eine solche Wahrnehmung treffen müssen, oder es hat gar keine Bedeutung" (A493/B521). Kant's idea seems to be that, prior to perceiving an object, to judge that it actually exists is to judge that if we were in the right conditions (if we were to continue the "Fortgang" of experiences appropriately) we must experience such an object. More formally:

(Ex.4) There is actually an object in space and time that has formally contingent property $\mathrm{F}$ if and only if [(a discursive spatiotemporal intellect is in the right conditions) $\rightarrow$ (that intellect experiences an object with property F)].

where $\rightarrow$ indicates some form of conditional relation. The difficult issue is how to understand this conditional. We cannot understand it as a material condition $(p \supset$ $q$ ), for, in the example above, if we never travel to region $\mathrm{R}$ or perform the observations necessary to determine whether it is occupied (e.g. using a telescope), the conditional would be trivially true, and it would follow that there is such an object. This has the absurd result that for every kind of object such that we will never be in the right conditions to experience such an object (e.g. unicorns in region R), there actually exists an object of that kind.

Nor can we understand it in terms of the 'strict' or necessitated conditional $((p \supset q))$, as might be suggested by Kant's invocation of what we "treffen müssen," for this would raise the question of what sense of necessity is involved here. Since the only relevant notion of necessity is formal necessity (what obtains in virtue of the forms of experience) $)^{39}$, this would entail in turn that it is inconsistent with the forms of experience that we be in the relevant conditions and fail to experience the object in question. This seems implausible. For instance, the 'right conditions' to experience a visible object are, intuitively, having a properly constituted visual system, having sufficient lighting, etc. But the forms of experience are no guarantee that we will not simply fail to see something in our field of vision.

Alternatively, we might read the counterfactual as a 'could' counterfactual $(p \diamond \rightarrow q)$ : if it were the case that $p$ then it could be the case that $q$. But this is too weak, for reasons related to the failure of the 'strict' conditional reading. The 'could' counterfactual might hold in a case where the antecedent of (Ex.4) (that there is such an object) does not, for some reason unrelated to the existence or nonexistence of the object. For instance, if I were to travel to a distant spatiotemporal

${ }^{39}$ Cf. Stang (2011) and Stang (2016a, Sect. 9.3). 
region R I could or might receive sensory matter that would be formed into an experience of a unicorn, but this would be due to a malfunction in my measuring device or my sense organs. This does not entail that $\mathrm{R}$ is occupied by a unicorn.

The best bet for the counterfactual analysis, then, is to interpret the counterfactual as a 'would' counterfactual:

(Ex.5) There is actually an object in space and time that has formally contingent property $\mathrm{F}$ if and only if [(a discursive spatiotemporal intellect is in the right conditions $) \rightarrow$ (that intellect experiences an object with property F)].

A corresponding version of (Prop) can easily be formulated:

(Prop.5) Where $x$ is an object in space and time, $x$ has formally contingent property $\mathrm{G}$, if and only if [(a discursive spatiotemporal intellect is in the right conditions) $\rightarrow$ (that intellect experiences $x$ as having property $\mathrm{G}$ )].

On this view, the ultimate ground of the existence of particular objects in space and time and their possession of their actual formally contingent properties is a subjunctive fact: what we would experience under certain conditions.

However, for this to be a viable option we need to say more about the antecedent of the 'would' counterfactual. Consider the following. It might be that if we were to investigate spatiotemporal region $\mathrm{R}$ we would find it occupied with matter with certain determinate actual properties, but if we were then to obtain a more comprehensive experience of the larger region $\mathrm{R}^{*}$ of which region $\mathrm{R}$ is a subregion, we would discover that our initial experience was mistaken: the objects in $\mathrm{R}$ have somewhat different properties then we initially thought, and our mistake was due to failing to consider their relation to the objects in the rest of $\mathrm{R}^{*}$. In this case, (Ex.5) as formulated has the counterintuitive result that the objects in R actually have the properties we initially experienced them to have.

To make this more concrete, consider the natural-scientific case on which Kant focused the most attention: Newton's determination of the true motions of the planets. On one influential reading of Metaphysische Anfangsgründe der Naturwissenschaft $(M A d N)$ Kant there reconstructs the process by which Newton constructed an inertial reference frame (a reference frame in which the three laws of motion are satisfied) in which to determine the true motions of the planets. ${ }^{40}$ The true motion of a body is not its motion with respect to absolute space, for that is not an object of possible experience, ${ }^{41}$ nor is it the motion it has with respect to any particular reference frame (what Kant calls an "empirical space"), for of any two reference frames in uniform rectilinear motion no possible experience

\footnotetext{
${ }^{40} \mathrm{I}$ am guided here by the interpretation of Friedman (1992); his interpretation is somewhat modified in Friedman (2013). On this point, I agree more with Friedman's earlier interpretation, though I do not have space here to explain my disagreements with the finer points of the meticulous analyses in Friedman (2013).

${ }^{41}$ MAdN, Ak. 4:559.
} 
can decide which is the 'correct' one. ${ }^{42}$ In Kantian terms, this means that the true motions of bodies are objects of possible experience up to equivalence of inertial reference frames in uniform rectilinear motion; consequently, only the acceleration of a body (which does not vary across the family of inertial frames) is a true property of the body (rather than a property that can be attributed either to the motion of the body or to the motion of the observer's reference frame). ${ }^{43}$

We determine the true motion (acceleration) of the Earth by finding a reference frame that takes the center of the solar system (which happens to be within the sun itself) to be stationary, the center-of-mass frame. ${ }^{44}$ But within this Newtonian project, one cannot stop with the center-of-mass frame of the solar system, for the solar system is rotating around the galactic center, thus subject to an attractive force towards that galactic center. Within a frame that takes the center of mass of the solar system to be stationary, the distant stars are undergoing an uncompensated force (a force that violates the first law of motion): they are rotating around the center of our solar system, thus being attracted to it (because they are undergoing an instantaneous change in velocity), without exerting a compensating force on that center. The solution is to construct a center-of-mass frame for the Milky Way itself, then for our local galactic group, the Virgo supercluster, etc.

To bring this example back to our discussion from earlier, the motions (accelerations) of the planets relative to the center-of-mass frame of the solar system are not their true motions simpliciter for they are motions within a very nearly but not exactly inertial frame (the motions of the distant stars violate the first law of motion in that frame). The motions of the planets within the solar system centerof-mass frame are very close approximations to their true motions. To get a closer approximation we need to proceed to the center-of-mass frame of the galaxy, which will be very nearly but not quite inertial (for the more distant galaxies are rotating around the Milky Way in this frame, thus being attracted to the Milky Way galactic center of mass without a compensating force). ${ }^{45}$ Therefore, the actual formally contingent properties of the Earth, in particular, its actual acceleration (which is formally contingent because it is not grounded solely in the forms of experience), are not the properties we would experience the Earth to have on the basis of a relatively complete pch-experience (e.g. the pch-experience constituted by Newton's complex calculation of the acceleration of the Earth relative to the center-of-mass frame of the solar system), but the properties we would experience the Earth to have on the basis of this process of constructing ever more complete experiences that asymptotically approach the true acceleration of the Earth. In other words, we need to revise (Prop.5) to:

\footnotetext{
${ }^{42} \mathrm{MAdN}$, Ak. 4:555-556.

${ }^{43}$ See the discussion of 'alternative' judgments at Ak. 4:556 and the footnote at 559-560.

${ }^{44}$ This relies on reading $M A d N$ as a reconstruction, within the contours of Kantian transcendental philosophy, of Newton's project in the Principia. On this point see Friedman (1992, pp. 159164) and the much more extensive discussion in Friedman (2013, esp. pp. 531-561).

${ }^{45}$ Cf. Friedman (1992, pp. 47-48), and Friedman (2013, pp. 156-158, 534-536).
} 
(Prop.6) Where $x$ is an object in space and time, $x$ has formally contingent property $\mathrm{G}$, if and only if [(a discursive spatiotemporal intellect has universal experience) $\rightarrow$ (that universal experience represents $x$ as having property G)].

A corresponding version of (Ex) can easily be formulated. This is why the skeptical scenario from above is impossible. If we were to construct ever more complete pch-experiences of objects, the resulting universal experience could not be inaccurate about which objects there actually are and which formally contingent properties they actually have, for these facts are grounded in how universal experience would represent objects if we had universal experience (if were to construct ever more complete pch-experiences).

By itself this is not especially informative because I have not yet said very much about the structure of universal experience. The point of this section, instead, has been to argue that universal experience plays a particular role in Kant's transcendental idealist view of spatiotemporal phenomena: it is the content of universal experience that grounds the existence of particular objects in space and time and their possession of their actual formally contingent properties. In the next section I will explain the form of universal experience, guided by this crucial desideratum: the form of u-experience must equip it to play this role in Kant's transcendental idealism. ${ }^{46}$

\section{The Form of Universal Experience}

I want to begin by picking up on two threads from the previous section. The first thread is that the process of constructing ever more complete pch-experiences (e.g. center-of-mass frames for the solar system, Milky Way, local group, Virgo supercluster, etc.) is in principle indefinitely continuable. The result of the first Antinomy is that we cannot say that the world in space and time is infinite, but neither can we say that it is finite: the progression from experience of one part of the world to experience of a more complete part can continue indefinitely. This means that whatever 'universal experience' is it is not the experience we have at

\footnotetext{
${ }^{46}$ One of the most important passages in the "Transcendental idealism as key" section is ambiguous on what kind of modal/subjunctive analysis Kant wants to employ: "Es ist im Ausgange ganz einerlei, ob ich sage, ich könne im empirisichen Fortgange im Raume auf Sterne treffen, die hundertmal weiter entfernt sind, als die äußersten, die ich sehe: oder ob ich sage, es sind vielleicht deren im Weltraume anzutreffen, wenn sie gleich niemals ein Mensch wahrgenommen hat, oder wahrgenommen wird" (A496/B524). I have argued though that it is very much not "einerlei" whether we say that there actually are such distant stars in virtue of the fact that we could experience them (too weak), or in virtue of the fact that they are there to be experienced (this is circular), or in virtue of the fact that if were in the right conditions we might experience them (too strong). I have argued that Kant should have said explicitly that we would experience them "im empirisichen Fortgange im Raume" if that "Fortgang" continued far enough.
} 
the 'end' of this process, for this process continues without end, ad indefinitum. Consequently, we are necessarily never in possession of the 'complete' u-experience. The second is that, since there can be only one u-experience ("the single all-encompassing experience"), none of these ever more complete experiences are themselves u-experience. Since they are not u-experience, given the varieties of experience distinguished in $\S 1$, they must be pch-experiences: relatively complete experiences of perceived and causally-hypothesized objects.

In the previous section, to give our quite abstract discussion a more concrete shape, I focused on the example of constructing ever more inclusive reference frames (empirical spaces) within Kant's reconstruction of Newton's physics. But this is merely a concrete example of Kant's theory of experience, not the theory itself, so we need to abstract from the details of that construction in order to see the form of $\mathrm{u}$-experience itself.

That form, as the discussion in the last two paragraphs has indicated, consists in a series of ever more complete pch-experiences. To make this more precise, we need a more precise account of what makes one pch-experience more complete than another. We will say that a pch-experience $\mathrm{E}^{*}$ is more complete than pch-experience $E$ just in case $E^{*}$ either (i) includes a larger spatial region than $\mathrm{E}$ or (ii) includes a wider range of objects within the same spatial region than $\mathrm{E}$ or (iii) includes a wider range of formally contingent properties than $\mathrm{E}$, but does not include $\left(\mathrm{i}^{*}\right)$ a narrower spatial region, nor (ii*) a narrower range of objects, nor (iii*) a narrower range of properties. For instance, if $\mathrm{E}$ is a pch-experience of a certain set of objects within a certain spatial region that represents a certain class of formally contingent properties of those objects, then a pch-experience can be more complete than $\mathrm{E}$ either by expanding the spatial region it represents, by representing objects not represented in E (e.g. the parts of the objects in E), or by considering formally contingent properties not considered by $\mathrm{E}$, but it cannot be restricted in any of these areas compared to E. I will assume that being more complete than is a strict ordering on experiences: it is asymmetric, irreflexive, and transitive.

We now have the materials to define a series of more complete experiences: a set of pch-experiences such that for every experience $E$ in the series there is an experience $\mathrm{E}^{*}$ in the series that is more complete than $\mathrm{E}$. This does not yet tell us where to fit $\mathrm{u}$-experience into this construction, but before we do that I want to address a limitation in the construction so far. As I have defined the series, it is possible to have a series that remains within a certain spatial region. For ease of exposition, let us start with an experience within the 1-unit radius sphere around $<0,0,0>$ (e.g. let the unit be the average distance of Pluto from the sun and $<0,0$, $0>$ be the center of mass of the solar system). Each experience $E_{n}$ represents the sphere of radius $2-1 /(n+1)$, where $n$ is any natural number. For any $m$ and $n$, the range of $E_{m}$ (the sphere of radius $2-1 /(m+1)$ ) will be greater than the range of $E_{n}$ (the sphere of radius $2-1 /(n+1)$ ) if and only if $m>n$ and E. It can be easily checked that $\left\{E_{n}\right\}$ satisfies the definition of a series of more complete experiences. But $\left\{E_{n}\right\}$ never breaks out of the sphere of radius 2 around $\langle 0,0,0\rangle$, even though each experience is more complete than the experiences 'prior' to it. 
To avoid this problem we need to impose the requirement that the series of more complete experiences is unbounded, and unbounded in three respects: (i) unbounded in spatial region, (ii) unbounded in domain, and (iii) unbounded in the properties it represents. With respect to (i) we need to impose the requirement that for any bounded region $\mathrm{R}$ of space there is an experience $\mathrm{E}$ in the series such that $\mathrm{R}$ is a proper sub-region of the region experienced in $\mathrm{E}$. With respect to (ii) matters are somewhat more complicated. We cannot say that every object must be represented by some experience in the series, for the very question at stake ((Ex) from earlier) is which objects there are, and since we are going to use the content of universal experience to answer this question, we cannot quantify over all objects in the construction of universal experience itself. Bear in mind further that Kant's view (articulated in the resolution of the second Antinomy) is that objects in space are not infinitely divided but infinitely divisible: for any region $\mathrm{R}$ filled with an object, any subregion of that region is a region that could have a part in it. ${ }^{47}$ So I think we should formulate (ii) as follows: for every region $\mathrm{R}$ explored by some experience, and for every object $x$ represented in $\mathrm{R}$ by some experience, and for every subregion of $\mathrm{R}$ occupied by $x$, there is some experience that represents an object in that subregion (a part of $x$ ). With respect to (iii) we need to impose the requirement that for every formally contingent property $\mathrm{F}$ and for every bounded region $\mathrm{R}$ of space and every experience that represents an object in that region, there is an experience that represents that object as determinate with respect to property $\mathrm{F}^{48}$ In other words, we need to require that the series of experiences is unbounded in spatial extent, domain of objects, and range of properties. I will refer to such a series as an unbounded series of ever more complete experiences.

Since universal experience is not any of the experiences in this series (because any of these experiences is incomplete relative to experiences later in the series) its content must supervene on the contents of the experiences in the series. But this is only possible if there is, in some sense to be specified, agreement in the content of the experiences that constitute the series. If each experience is radically revised by the next experience in the series, then there will be no answer to the question: what does a universal experience supervening on this series represent?

We can simultaneously specify the way in which the content of universal experience supervenes on the content of the experiences in the series and make precise the vague idea of 'agreement' among the contents of the experiences in the series by applying the mathematical notion of a limit. The formally contingent properties of spatiotemporal objects that Kant's account is meant to ground are magnitudes,

\footnotetext{
${ }^{47} \mathrm{~A} 525 / \mathrm{B} 553$.

${ }^{48}$ Readers concerned that this depends upon the transcendental illusion of assuming that the complete space of possible properties is 'given' should see Stang (2012) for further discussion, as well as Stang (2016a, pp. 290-292).
} 
that is, properties that can be assigned a quantitative value. ${ }^{49}$ In particular, they will have a continuous value, representable as a real number, given some unit. ${ }^{50}$ They will include intensive magnitudes (degree of attractive force, density, acceleration) as well as extensive magnitude (volume, length, etc.). So universal experience, whose content grounds which formally contingent properties spatiotemporal phenomena actually have, will assign numerical values to these properties. Consequently, we can construct the content of universal experience as the limit of the contents of the experiences in the series. This will render precise the sense in which universal experience supervenes on the series and the sense in which the experiences in the series must 'agree' (the values they assign to various properties must converge-see below).

Intuitively, an unbounded series of successively more complete experiences renders a determinate verdict on the magnitude of a property of an object when the values the experiences in the series assign to the property converge. The experiences converge to a determinate value $v$ just in case for any $\varepsilon>0$ there is an experience $\mathrm{E}$ such that for any experience $\mathrm{E}^{*}$ more complete than $\mathrm{E}$ (symbolized $\mathrm{E}^{*}>\mathrm{E}$ ) the difference between $v$ and the value assigned to that property by experience $\mathrm{E}^{*}$ is less than $\varepsilon$. If $\left\{E^{n}\right\}$ is an unbounded series of ever more complete pch-experiences $\left(E_{n}>E_{m}\right.$ if and only if $\left.n>m\right)$ and $F_{n}^{x}$ represents the value assigned to property $\mathrm{F}$ for object $x$ by experience $\mathrm{E}_{\mathrm{n}}$, then this means that the series $\left\{\mathrm{F}_{\mathrm{n}}^{x}\right\}$ converges to a value $v$. We can thus fill in the blank in (Prop) from $\S 3$ in full generality as follows:

(Prop.7) Where $x$ is an object in space and time, $x$ has formally contingent property $\mathrm{F}$ with value $v$, if and only if [(a discursive spatiotemporal intellect has an unbounded series of ever more complete experiences) $\rightarrow$ (the series of values those experiences assign to $\mathrm{F}$ for $x$ converge to $v$ )].

\footnotetext{
${ }^{49}$ In $K r V$ Kant argues that all objects of experience überhaupt have quantitatively determinate extensive magnitudes (Axioms of Intuition, A161/B202) and intensive magnitudes (Anticipations of Perception, A165/B207). This is what makes possible the application of mathematics to objects of experience in general. In $M A d N$ he argues for the more specific claim that all bodies (outer objects composed of matter, the movable in space) have quantitatively determinate motions (Phoronomy), fill quantitatively determinate regions of space (Dynamics), and exert quantitatively determinate forces upon one another (Mechanics). This is what makes possible the application of mathematics to bodies. An extensive magnitude is one, the representation of which requires representing its parts; an intensive magnitude is a degree of reality, not possessed in virtue of having a multiplicity of parts. Kant's categorization of various magnitudes (e.g. velocity, mass, force) as either intensive or extensive is complicated and I cannot go into the details here.

${ }^{50}$ The continuity of the extensive magnitude of objects (between any two extensive magnitudes an intermediate magnitude is possible) follows from the continuity of space (A169/B211). The continuity of intensive magnitude is more complicated; Kant argues for it in the Anticipations of Perception (B208). The Anticipations of Perception, and the idea of continuity and intensive magnitude, became deeply significant for Cohen's Kant interpretation and his systematic philosophy, starting with the publication of PIM in 1883 and continuing with $K T E^{2}$ in 1885 ; see his discussion of Kant's theory of intensive magnitudes in PIM, 105-113, and $K T E^{3}, 538-562$, as well as the discussion of these themes in his systematic work $L R E, 418-420,462-464$.
} 
The convergence of this series is defined as above.

I will conclude this section by noting two desirable features of this construction. First of all, it does not assume that universal experience will converge for every property of every object. For instance, the location and velocity of bodies will not converge, for as we proceed to ever greater reference frames (ever more complete experiences) the series of positions and velocities assigned to a given body (e.g. the Earth) will diverge. This entails that there is no determinate fact of the matter about the position or velocity of bodies; the determinate formally contingent properties they actually possess are, for instance, their position (and velocity) relative to other bodies in a given inertial frame and their acceleration. It makes no sense to ask whether a body is moving or at rest or where it is located simpliciter, but it does make sense to ask what the magnitude of its acceleration is simpliciter. Secondly, this construction can easily make room for the idea that objects may not have fully determinate values with respect to certain properties, but may only possess properties within a range of values. The construction can make room for this possibility by replacing the value $v$ with a range of values $[v-\delta, v+\delta]$ where the difference between this interval and $\mathrm{F}_{\mathrm{n}}^{x}$ is understood as the maximum difference between $\mathrm{F}_{\mathrm{n}}^{x}$ and any point in $[v-\delta, v+\delta]$. If that difference (between $\mathrm{F}_{\mathrm{n}}^{x}$ and $[v-\delta, v+\delta]$ ) converges then object $x$ determinately has property $\mathrm{F}$ with a value within the range $[v-\delta, v+\delta]$ but does not possess any fully determinate value within that range. ${ }^{51}$

The construction of universal experience proposed so far, (Prop.7), applies only to the formally contingent properties of objects that are magnitudes (continuously gradable properties). It will not apply to the existence of objects, because existence is not a magnitude (because it is not a real predicate at all), so it is not, by itself, an answer to (Ex) from above. However, a corresponding version of (Ex) can easily be formulated. It might be that some experience in a series posits the existence of an object of a particular kind (one with formally contingent property F), but 'later' experiences in the series (more complete experiences) would reject that posit. For instance, one experience would posit the existence of a magnetic field, while a later more complete experience rejects this posit in favor of an immediate magnetic action-at-a-distance (without a material medium). What corresponds, in the case of existence, to a series of experiences converging on a particular value, is a series in which one experience posits the existence of an object of a particular kind, and every experience more complete than that experience posits the same object. We will say that an unbounded series of ever more complete experiences converges to the existence of an $F$ just in case there is some experience $\mathrm{E}$ in the series that represents an $\mathrm{F}$ as existing (its content includes: there is an $x$ such that $\mathrm{F} x$ ), and every experience more complete than $\mathrm{E}$ represents an $\mathrm{F}$ as existing (its content includes: there is an $x$ such that $\mathrm{F} x$ ). We can then 'fill in' the blank in (Ex) as follows:

\footnotetext{
${ }^{51}$ This is a desirable feature of the construction because it allows for a middle way between the extremes of an object being wholly indeterminate with respect to a property or having a fully determinate value with respect to that property.
} 
(Ex.7) There is actually an object in space and time that has formally contingent property $\mathrm{F}$ if and only if [(a discursive spatiotemporal intellect has an unbounded series of more complete experiences) $\rightarrow$ (that series converges to the existence of an F)].

Note this does not mean that for any experience in the series that posits the existence of an F, every experience more complete than it will also posit the existence of an F. All that is required is that there is some point in the series where an F is posited, and 'after' that point that posit is never rejected.

Universal experience is not any member in such a series, nor is it entirely accurate to describe it as the whole series itself. The series, recall, may include experiences whose content is later rejected or radically revised: "wenn man von verschiedenen Erfahrungen spricht, so sind es nur so viel Wahrnehmungen, sofern solche zu einer und derselben allgemeinen Erfahrung gehören" (A110). So it would not be correct to assume that all experiences in a series are parts of universal experience itself. Instead, my analysis of universal experience shows universal experience not to be any individual entity — not the series, not any element in the series. Instead, we have shown how to translate claims about universal experience into claims about such an unbounded converging series of more complete experiences. We can intelligibly make claims with a determinate truth-value about universal experience, but there is no individual item in our ontology that can be identified as universal experience. But this is precisely what we should expect. For every experience, there can be a more complete experience, so universal experience is not an experience or object of experience. Universal experience is what Kant calls a 'regulative idea': an idea of a complete totality that can never be presented in or manifested by (pch-)experience but which guides our rational inquiry into nature. Similarly, the world as a complete totality of objects in space and time is not a possible object of (pch-)experience, so there is no item in our ontology that can be identified as the world. But we can give claims about the world a determinate truth-value; for instance, it is false that the world is finite, because for any world-part there is a larger world-part that contains it. Similarly, we can give determinate truth-values to claims about universal experience by translating them into claims about unbounded complete series of more complete experiences.

\section{Cohen's Theory of Experience}

In $\S 1$ I argued that Kant sometimes uses the term 'experience' not to refer to a perceptual episode of a given subject, but to something I called 'universal experience.' In $\S 2$ I argued that universal experience plays an important role in Kant's transcendental idealism: it grounds the actual formally contingent properties of spatiotemporal objects. In $\S 3$ I offered a 'limit' construction of universal experience, according to which its content is the asymptotic limit of a converging sequence of ever more complete causal-hypothetical experiences. In this section, I conclude 
by bringing all of this back to the original topic of this article: Hermann Cohen's interpretation of Erfahrung in $K T E$.

"Kant invented a new concept of experience," Cohen writes at the beginning of KTE. Before going on to characterize Cohen's own positive account of what Erfahrung is, it is important to be clear on what kind of interpretation he is rejecting. While this point is less clear in $K T E^{1}$, in $K T E^{2}$ it is abundantly clear that Cohen is opposed to any conception of Erfahrung that takes it to be what I will call a 'psychological' notion: Erfahrung does not refer, according to Cohen, to conscious mental or perceptual episodes in individual subjects' minds. ${ }^{52} \mathrm{On}$ any such 'psychological' conception of experience, 'experience' is a count noun: my experience is a different experience than yours, and my experience now is a different experience than my experience ten minutes ago. Cohen's rejection of this notion of experience is part and parcel of his rejection of the idea that Kant is giving a theory of cognitive processes or a psychological theory of any kind. While I think there is more psychology in Kant's theory than Cohen allows for (at least by the time of $K T E^{2}$ ), my arguments up to this point make clear that Cohen is correct, to this extent: there is a central (perhaps the central) notion of experience in Kant that is not 'psychological' in this sense and not individual (there is only one u-experience). It is what I have called u-experience.

In KTE Cohen identifies Erfahrung as mathematical natural science. ${ }^{53}$ In and of itself this is somewhat vague, so we must do some work to understand it. Thinking of Erfahrung as 'science' can mislead us, if we think of science as consisting of theories, i.e. discursive artifacts created by human beings. Erfahrung is not itself a scientific 'theory,' although, like a scientific theory, it has a content more determinate than any perceptual episode or sequence of such episodes in an individual consciousness. In this context it might be helpful to recall Kant's own definition of Wissenschaft in the Jäsche Logik: "vom Wissen kommt Wissenschaft her, worunter der Inbegriff einer Erkenntniß als System zu verstehen ist" (Ak. 9:72). Borrowing this idea, we can say that Erfahrung, for Cohen, is (at least) systematically unified knowledge of its object. Erfahrung is natural science insofar as its object is nature, all objects in space and time. That Erfahrung is mathematical natural science (Naturwissenschaft) means that its content is mathematical: it represents its object (nature) as having quantitative properties that stand in mathematical relations. As I argued in $\S 3$, the properties u-experience represents its objects as having are magnitudes, which necessitated the complex limit construction I gave in that section.

\footnotetext{
${ }^{52}$ Cohen's anti-psychologism is complicated in $K T E^{1}$ by his (atavistic?) commitment to Herbartian psychology $\left(K T E^{1}\right.$, pp. 122, 128); in $K T E^{2}$ and $K T E^{3}$ he is more clearly opposed to any psychological interpretation of Erfahrung. See Beiser 2010, p. 487 (as well as Edel's Introduction in $K T E^{3}$, p. $\left.19^{*}\right)$ on the Herbartian strand in $K T E^{1}$.

53“"Kants Aufgabe ist also zunächst die Prüfung und Kennzeichnung des Erkenntniswertes und des Gewissheitsgrundes der Netwonschen Naturwissenshcaft, welche er be dem Drohwort der Erfahrung fasste" $\left(K T E^{3}\right.$, p. 93$)$.
} 
Insofar as this is what Cohen means by saying in $K T E^{1}$ that Erfahrung is mathematical natural science his interpretation is partly vindicated by the arguments of $\S \S 1-3$. However, already in $K T E^{1}$ and increasingly in $K T E^{2}$, Cohen has a tendency to identify Erfahrung specifically with Newtonian mathematical natural science. The question is, what does Cohen mean by characterizing Kantian experience as specifically Newtonian mathematical natural science? There are at least three things Cohen might mean by this. First, he might mean merely that Kantian experience is inspired by Newton and has some overlap in content with Newton's theory. Secondly, he might mean to identify Kantian experience with Newton's specific theory of heavenly motion in Philosophiae naturalis principia mathematica. Thirdly, he might mean something intermediate between the weak first reading and the strong (and implausible) second reading: that Newton's theory, like Kantian universal experience, constructs its object—nature-in a sense of 'construction' to be explicated below.

Regarding the first reading, one clear source for Kant's idea of an unbounded series of more complete experiences, whose asymptotic limit is universal experience, is the Newtonian project of determining the true motions of bodies with respect to ever more complete cosmic reference frames (from the solar system, to the Milky Way, etc.). ${ }^{54}$ What is more, Kant thinks that universal experience of matter has specifically Newtonian content: it represents bodies as obeying the Newtonian laws of motion and as exerting a universal immediate attractive force on one another. The project of $M A d N$ is to introduce "principles for the construction of the concepts that belong to the possibility of matter," 55 which I interpret to mean: specifying the a priori rules by which we transform the perception of matter into experience of matter. In terms of my distinctions among different senses of Erfahrung in Kant's system, this means: transforming mere p-experience of matter (experience of a body as intersubjectively accessible) into pch-experience of matter (experience of a body that abstracts from sensory content due to the contingent nature of my sense organs from and the particular position and motion of my reference frame). ${ }^{56}$ Kant argues in $M A d N$ that experience of matter in this sense requires that we represent matter as obeying Newton's three laws of motion and as exerting an immediate attractive force on all other matter. Since universal experience of matter is the asymptotic limit of an unbounded series of more complete such experiences of matter, universal experience of matter will also have a Newtonian content. It will represent matter as obeying Newton's three laws of motion and exerting an immediate attractive force on all other matter.

\footnotetext{
${ }^{54}$ See the references to Friedman in note 44.

${ }^{55} \mathrm{MAdN}, \mathrm{Ak} .4: 472$.

${ }^{56} \mathrm{Ak}$. 4:298. I cannot here go into detail on the my interpretation of the relation among the different senses of experience distinguished in $\$ 2$ and the Prolegomena distinction between judgments of perception and judgments of experience.
} 
However, regarding the second reading, Cohen would be wrong to read Kant as assuming the truth of Newtonian natural science as a fact $^{57}$ and engaging merely in the regressive search for the conditions of its possibility. In the $\mathrm{KrV}$ Kant argues for the claim that nature is quantitatively and causally determinate, and that mathematical natural science in general is therefore possible. In $M A d N$ he argues further that objectively valid experience of matter must have specifically Newtonian content and thus grounds the possibility of Newtonian science. He assumes neither the possibility of mathematical natural science nor the actuality of specifically Newtonian natural science..$^{58}$

But a reading intermediate between the almost vacuous first reading and the highly implausible second reading is possible: Cohen may mean that Kantian experience is Newtonian in the sense that it 'constructs' its object, nature. What exactly 'construction' means for Kant or for Cohen (or, for that matter, Newton) is a complex question to which I cannot give anything more than a sketch of an answer here. But even this sketch will help us to see that, in characterizing Kantian (universal) experience as Newtonian (read: constructive) mathematical natural science, Cohen is not necessarily misreading Kant. Whatever 'construction' means it is clear that it does not mean, either for Cohen or for Kant, literal creation. Kant and Cohen are united in their opposition to any kind of subjective idealism on which the object of experience, nature, is caused to exist by the intellectual activity of human subjects. ${ }^{59}$ In $M A d N$, the text in which Kant is most closely engaged with Newton, Kant describes himself as introducing "Principien der Construction der Begriffe, welche zur Möglichkeit der Materie überhaupt gehören"60 which I read as meaning: providing the a priori rules by which we transform mere perception of motion into experience. Building on the interpretation in $\S \S 2-3$ we can say further that these a priori rules make possible pch-experience of matter, the pch-experiences that constitute the 'stages' in the converging series by which we define universal experience. So the 'objective' motions of bodies, the motions they actually have (not merely the motions they possible have, or are experienced to have at one or another pch-experience stage), are defined in terms of a sequence of pch-experiences structured according to these a priori rules. What it is for a

\footnotetext{
${ }^{57}$ What Cohen calls "das Faktum der Wissenschaft" (KTE 1 , pp. 41, 94).

${ }^{58}$ Various scholars have made the point that Cohen effectively conflates the "analytic" method of the Prolegomena with the "synthetic" method of the $K r V$; see Beiser (2014, p. 489) and Luft (2015, pp. 224-225). In Cohen's defense, he is aware of this distinction and explicitly argues that Kant in fact adopts an analytic or regressive method in the $\mathrm{KrV}$.

${ }^{59}$ One might think that we can address the sense in which we 'construct' nature in experience by appeal to Kant's theory of geometric construction in pure intuition, but there are two barriers to this. First, Kant distinguishes between objects of pure intuition (mathematical objects) and concrete causally efficacious objects in space and time, the objects that constitute nature, the objects of experience (mathematical natural science). Construction of the latter, whatever it is, is going to be quite different than construction of the latter. Secondly, the whole notion of mathematical construction in pure intuition is itself a complex one in Kant, so we might be in danger of explain obscurum per obscurius.

${ }^{60} \mathrm{Ak} .4: 472$.
} 
body to have a particular motion is defined in terms of pch-experiences which are themselves constructed according to these a priori rules. Abstracting slightly from the technical terminology of Kantian philosophy (a priori rules, etc.), we can say that from this perspective Newton's laws are not merely observed regularities in the motions of planets, nor do they merely give us epistemic warrant for making judgments about those motions: they are partly constitutive of those motions themselves. It is not as though we have some independent grasp on the notion of the objective motions of bodies and then we either observe that the laws are obeyed by these motions, or these laws give us warrant to make judgments about those motions; the concept of the objective motions of bodies has no meaning for us unless we represent them as the motions bodies have in a reference frame in which those laws are obeyed, an inertial frame. The laws of motion, on this reading, 'construct' their object in that they make that object itself possible. If this is what Cohen means by calling Kantian experience Newtonian mathematical natural science, then he is correct, insofar as we follow Kant's understanding of Newton. Kantian experience is Newtonian insofar as it takes its most fundamental laws (the transcendental principles of experience) not to be observed regularities, but constitutive principles that make its object (motion). ${ }^{61}$ Thus we see that Cohen's long-decried reading of Kant is correct in what is perhaps its most central claim: Kantian experience is Newtonian (because constructive) mathematical (because its content is quantitative) natural (because its object is nature as a whole) science (because it is systematic cognition of that object).

Another aspect of Cohen's interpretation of Kant partly vindicated by my own account is his notorious identification of things in themselves (Dinge an sich selbst) with the limit of natural scientific inquiry. In both the first and second editions of Kants Theorie der Erfahrung Cohen identifies things in themselves not with a separate realm of objects distinct from phenomena (so-called 'two object' readings) nor with an unknowable inner properties of phenomena (the now dominant metaphysical 'one object' reading) nor with a 'transcendental' perspective on objects that abstracts from the specifically spatiotemporal conditions of our cognition of them (the 'epistemological' reading made famous in English-language scholarship by Henry Allison). ${ }^{62}$ Cohen identifies the concept of the thing in itself with the concept of objects as they would be represented at the never-to-be-obtained limit of experience, the 'final' theory of them in natural science. The critical function of the concept of the thing in itself, according to Cohen, is to remind

\footnotetext{
${ }^{61} \mathrm{My}$ argument here, even some of my formulations, are clearly indebted to the work of Michael Friedman here. However, given my explicit construction of universal experience and my more 'idealist' reading of how phenomena depend on universal experience (see $\S \S 2-3$ ) I claim something stronger than Friedman: what it is for an object to have a certain motion is for it to be represented as having that motion in a universal experience whose stages are constructed using Newtonian laws. I do not have the space here to explore this deviation from Friedman's less 'metaphysical' reading.

${ }^{62}$ For this tripartite classification of interpretations of transcendental idealism see the classic paper Ameriks (1982).
} 
us that we have never reached 'final science,' that our experience, no matter how complete, could always be more complete. Experience is indefinitely continuable and cannot be given to us as an actual infinite totality.

My interpretation of Kant's theory of experience retains a role for the idea of the asymptotic limit of an unbounded series of ever more complete experiences: the actual properties of phenomena are the properties represented at this asymptotic limit. This means that the asymptotic limit of experience is associated, not with the 'transcendental' distinction between things and themselves and appearances, with which Cohen and most commentators on Kant's idealism are primarily concerned, but the 'empirical' distinction between how phenomena appear to us at any particular stage in perception or (pch-)experience and the empirical properties they really have. Kant explains this distinction through the example of a rose: "in diesem Falle gilt das, was ursprünglich selbst nur Erscheinung ist, z. B. eine Rose, im empirischen Verstande für ein Ding an sich selbst, welches doch jedem Auge in Ansehung der Farbe anders erscheinen kann" (A29/B45). This is the distinction between the properties we attribute to the phenomena on the basis of the subjective constitution of our sense organs (e.g. their color) and properties they objectively possess (e.g. extension). It is a distinction within the empirical cognizable properties of bodies, so it is not a transcendental distinction between objects as they appear (phenomena) and as they are in themselves (noumena). On my interpretation, the properties the rose actually possesses are the properties it would be represented as having in the asymptotic limit of a series of ever more complete experiences (see previous section). ${ }^{63}$ Thus, from my perspective Cohen is right to identify the thing in itself as the limit of natural scientific inquiry, but only if we restrict this to the 'empirical' concept of a thing in itself: a phenomenon as it is in itself, independently of how it is pch-experienced by any particular subject at any particular time.

There are other aspects of Cohen's Kant interpretation that, for reasons of space, I have not addressed here - e.g. his non-psychological reading of the $a$ priori, the idea of the 'transcendental,' the subordination of sensibility to thought in $K T E^{2}$, etc. I do hope, however, to have convinced the reader that, while Cohen's interpretation of Kant's theory of experience cannot be endorsed without qualification, it contains a kernel of insight that contemporary Kant scholars should not ignore. But neither should scholars of Cohen. If I am right that Cohen's interpretation of Kant's theory of Erfahrung is, in broad strokes, correct, then our understanding of Marburg Neo-Kantianism, which often operates under the (at least) implicit assumption that the Marburg reading of Kant is fundamentally a misreading, may need to be revised. ${ }^{64}$

\footnotetext{
${ }^{63}$ In a parallel discussion at A45/B63, Kant distinguishes between a rainbow as an appearance in the empirical sense (in which it is colored) and as a thing in itself in the empirical sense (in which it is a collection of colorless raindrops). He identifies the rainbow 'in itself' as the rainbow as it is represented in "allgemeine Erfahrung."

${ }^{64}$ I would like to thank Christian Damböck and the audience at a conference at the University of Vienna in the Fall of 2014 for their questions and feedback on an earlier draft of this paper. Special thanks also to Ian Drummond for excellent copy-editing.
} 


\section{Abbreviations for Works of Cohen}

KTE Kants Theorie der Erfahrung. Superscript indicates edition: $1^{\text {st }}$ edition (1871) in Werke I.3, $3^{\text {rd }}$ edition (1918) in Werke I.1, which also contains marginal paginations for the $2^{\text {nd }}$ edition (1885)

LRE Logik der reinen Erkenntnis (1914). $4^{\text {th }}$ edition. Werke 6

PIM Prinzip der Infinitesimal-Methode und seine Geschichte (1883). In Werke 5

Werke Hermann Cohen, Werke. Ed. Hermann-Cohen Archiv am Philosophischen Seminar der Universität Zürich unter der Leitung von Helmut Holzhey. Hildesheim, Zürich, New York: Georg Olms, 1984

\section{Abbreviations for Works of Kant}

Ak. Kants gesammelte Schriften (vols. 1-29). Berlin-Brandenburg (formerly: Royal Prussian) Academy of Sciences (eds.). Berlin: Walter de Gruyter, 1902. Cited by volume and page number

KrV Kritik der reinen Vernunft (A:1781, B:1787). Ak. 3 (B) and 4: 1-252 (A)

MAdN Metaphysische Anfangsgründe der Naturwissenschaft (1786). Ak. 4: 465-566

Prol. Prolegomena zu einer jeden künftigen Metaphysik die als Wissenschaft wird auftreten können (1783). Ak. 4: 253-384

\section{References}

Allais L (2015) Manifest reality: Kant's idealism and his realism. Oxford University Press, Oxford

Ameriks K (1982) Recent work on Kant's theoretical philosophy. Am Philos Q 19(1):1-24

Beiser F (2002) German idealism: the struggle against subjectivism 1781-1801. Harvard University Press, Cambridge (Mass.)

Beiser F (2014) The genesis of Neo-Kantianism, 1796-1880. Oxford University Press, Oxford

Brandt R (1993) Hermeneutik und Seinslehre bei Hermann Cohen. In: Brandt R, Orlik F (eds) Philosophisches Denken-Politisiches Wirken: Hermann Cohen-Kolloquium Marburg 1992. Olms, Hildesheim, pp 37-54

Friedman M (1992) Kant and the exact sciences. Harvard University Press, Cambridge (Mass.)

Friedman M (2013) Kant's construction of nature: a reading of the metaphysical foundations of natural science. Cambridge University Press, Cambridge

Heidegger M (1929) Kant und das Problem der Metaphysik. Vittorio Klostermann, Frankfurt a. M.

Köhnke KC (1986) Entstehung und Aufstieg des Neukantianismus. Suhrkamp, Frankfurt a. M.

Kuehn M (2009) Interpreting Kant correctly: on the Kant of the Neo-Kantians. In: Makkreel R, Luft S (eds) Neo-Kantianism in contemporary philosophy. Indiana University Press, Bloomington, pp 113-131

Langton R (1998) Kantian humility. Oxford Univeristy Press, Oxford

Luft S (2015) The philosophy of the Marburg school: from the critique of scientific cognition to the philosophy of culture. In: Warren N de, Staiti A (eds) New approaches to Neo-Kantianism. Cambridge University Press, Cambridge, p 221-239 
Poma A (1997) The critical philosophy of Hermann Cohen. SUNY Press, Albany

Stang N (2011) Did Kant conflate the necessary and the a priori? Noûs 45(3):443-471

Stang N (2012) Kant on complete determination and infinite judgment. Br J Hist Philos 20(6):1117-1139

Stang N (2015a) Who's afraid of double affection? Philosophers' Imprint 15(8):1-28

Stang N (2015b) Kant's argument that existence is not a determination. Res 91(3):583-626

Stang N (2016a) Kant's modal metaphysics. Oxford University Press, Oxford

Stang N (2016b) Appearances and things in themselves: actuality and identity. Kant Rev 21(2):283-292

Vaihinger H (1892) Commentar zu Kants Kritik der reinen Vernunft, Vol 2. Spemann, Stuttgart 